\title{
THE EFFECT OF MORAL INTEGRITY, LIFESTYLE AND ORGANIZATIONAL CULTURE ON ANTI- CORRUPTION INTENTION
}

\author{
Dhiny Aditama Putri \\ aditamadhiny@gmail.com \\ Anggota HIMPSI Provinsi Banten
}

\author{
Zahrotun Nihayah \\ Zahrotun.nihayah@gmail.com \\ Fakultas Psikologi UIN Syarif \\ Hidayatullah Jakarta
}

\begin{abstract}
This study aims to examine the effect of moral integrity, lifestyle and organizational culture on anticorruption intention involving 54 police officers and 97 civil servants of police in police institution $X$. Sampling technique in this study using non-probability sampling. The measuring tool used in this study consists of the Anti Corruption Intelligence Scale which the authors develop themselves to measure the anti-corruption intention, Moral Integrity Scale to measure moral integrity, AIO Psychographic to measure lifestyles, and the Denison Organizational Culture Survey to measure organizational culture. Confirmatory Factor Analysis (CFA) was used to test the validity of measuring instrument and Multiple Regression Analysis is used to test the research hypothesis. The results revealed that there was a significant of moral integrity, lifestyle and organizational culture against anti corruption intention at 56.3\%. It means that the proportion of varians of anti-corruption intention in can be explained by moral integrity, lifestyle, and organizational culture at $56.3 \%$ and $43.7 \%$ explored by other factors.
\end{abstract}

Keyword: Moral integrity, Lifestyle, Organizational culture, Anti-corruption intention, Confirmatory Factor Analysis (CFA)

\begin{abstract}
Abstrak
Penelitian ini bertujuan untuk menguji pengaruh integritas moral, gaya hidup dan budaya organisasi terhadap intensi anti korupsi melibatkan 54 anggota polisi dan 97 PNS polri pada lembaga kepolisian X. Pengambilan sampel yang dilakukan menggunakan non probability sampling. Alat ukur yang digunakan dalam penelitian ini terdiri dari Skala Intensi Anti Korupsi yang penulis kembangkan sendiri mengukur intensi anti korupsi, Moral Integrity Scale untuk mengukur integritas moral, AIO Psychographic untuk mengukur gaya hidup, dan Denison Organizational Culture Survey untuk mengukur budaya organisasi. Uji validitas alat ukur menggunakan teknik Confirmatory Factor Analysis (CFA) dan teknik analisis data menggunakan teknik analisis regresi berganda. Hasil penelitian menunjukkan bahwa ada pengaruh yang signifikan integritas moral, gaya hidup dan budaya organisasi terhadap intensi anti korupsi sebesar 56,3\%. Artinya, proporsi varians dari intensi anti korupsi yang dijelaskan secara bersama-sama oleh signifikan integritas moral, gaya hidup dan budaya organisasi adalah sebesar $56,3 \%$ sementara $43,7 \%$ lainnya dipengaruhi oleh variabel lain diluar penelitian ini.
\end{abstract}

Kata kunci: Moral integrity, Gaya hidup, Budaya organisasi, Intensi anti korupsi, Confirmatory Factor Analysis (CFA)

Diterima: 12 Oktober 2016 Direvisi: 16 November 2016 Disetujui: 21 Desember 2016 


\section{PENDAHULUAN}

Beberapa tahun belakangan ini, korupsi menjadi permasalahan yang sangat sering terjadi di Indonesia ini. Budaya korupsi seakan memperoleh lahan yang subur di Indonesia karena sifat sebagian besar masyarakat yang lunak, sehingga permisif terhadap berbagai penyimpangan moral dalam kehidupan bermasyarakat, berbangsa dan bernegara. Keadaan yang demikian inilah yang menyebabkan persoalan korupsi di Indonesia dianggap sebagai perkara biasa yang wajar terjadi dalam kehidupan masyarakat (Suraji, 2008).

Lembaga Transparency International Indonesia (TII) merilis data Coruption Perception Index untuk tahun 2016. Skor indeks persepsi korupsi Indonesia tahun 2016 meningkat tipis satu poin dari skor yang diperoleh pada tahun 2015, yaitu sebesar 37. Skor CPI berada pada rentang 0-100. 0 berarti negara dipersepsikan sangat korup, sementara skor 100 berarti dipersepsikan sangat bersih dari korupsi. Kenaikan skor ini menandakan masih berlanjutnya tren positif pemberantasan korupsi di Indonesia. Dalam laporan tersebut, Indonesia menempati urutan ke-90 dari 176 negara yang diukur indeks persepsi korupsinya. Di Asia Tenggara, posisi indeks persepsi korupsi Indonesia berada di bawah Singapura, Malaysia, dan Brunei (Transparency International Indonesia, 2016).

Pada tahun 2017 ini, berita-berita mengenai tindak pidana korupsi di Indonesia pun semakin banyak diberitakan di media massa dan menjadi topik pembicaraan di berbagai kalangan. Semakin maraknya kasus-kasus korupsi yang terjadi di Indonesia, hal itu membuat masyarakat yang mendengarnya menjadi biasa saja. Para pelaku korupsi ini mayoritas berasal dari institusi-institusi milik Negara, seperti DPR, kepolisian, kejaksaan agung, mahkamah konstitusi maupun lembaga-lembaga negara lainnya, walaupun tidak sedikit juga pelaku tindak pidana korupsi berasal dari lembaga swasta ataupun dari partai politik.

Berdasarkan data dari Komisi Pemberantasan Korupsi (KPK), pada tahun 2017 ini, pertanggal 30 Juni 2017, berdasarkan pada jenis perkaranya, KPK telah melakukan penanganan terhadap 49 kasus perkara korupsi, yang sebagiannya berasal dari jenis penyuapan sebanyak 37 kasus, penyalahan anggaran sebanyak 1 kasus, korupsi pengadaan barang dan jasa sebanyak 8 kasus, tindak pidana pencucian uang sebanyak 2 kasus, dan 1 kasus mengenai korupsi perijinan. Sedangkan, apabila melihat tindak pidana korupsi berdasarkan pada instansinya, per 30 Juni 2017, menurut KPK penanganan tindak pidana korupsi di tahun 2017 ini lebih banyak ditemukan di kementerian/lembaga sebanyak 19 perkara, Pemerintah Provinsi sebanyak 10 perkara, DPR dan DPRD sebanyak 7 perkara, dan BUMN/BUMD sebanyak 11 perkara (KPK, 2017).

Kepolisian Republik Indonesia disebut sebagai lembaga negara paling korup di negara kesatuan republik Indonesia. Hal tersebut diungkapkan oleh Centre For Strategic and International Studies (CSIS), US AID, dan Management Systems International (MSI). Dari hasil survey opini publik yang telah dilakukan di 34 provinsi dengan 3900 responden warga Negara Indonesia, Sebanyak 59,8 \% responden mengaku pernah diminta untuk menyuap oleh pihak kepolisian republik Indonesia, sementara 38,6 \% mengaku pernah memberikan suap, dan hanya 32,9 \% sisanya tidak diminta maupun memberikan suap (Merah Putih, 2016). 
Selain itu, berdasarkan hasil survei yang diselenggarakan oleh Komisi Pemberantasan Korupsi (KPK) pada tahun 2015 mengenai indeks integritas lembaga pemerintahan. Kepolisian Republik Indonesia berada di posisi lima terbawah dari 20 lembaga/instansi pemerintahan yang terlibat, dengan perolehan angka indeks integritas pusat (IIP) sebesar 6,32, dimana angka tersebut berada di bawah angka rata-rata indeks integritas pusat. Rendahnya angka indeks integritas yang diperoleh Kepolisian Republik Indonesia menunjukkan bahwa masih banyaknya praktik suap dan gratifikasi dalam pelayanan publik di instansi tersebut (Komisi Pemberantasan Korupsi, 2015).

Berdasarkan latar belakang yang telah peneliti jabarkan diatas, peneliti tertarik untuk melakukan penelitian mengenai "Pengaruh integritas moral, gaya hidup dan budaya organisasi terhadap intensi anti korupsi".

\section{KAJIAN TEORI}

Banyak sekali faktor-faktor yang dapat menyebabkan seseorang terjerumus ke dalam tindak pidana korupsi, baik faktor dari dalam diri individu (faktor internal), maupun faktor yang berasal dari lingkungan atau yang berada di luar diri inidividu (faktor eksternal).

Faktor pertama yang dapat mempengaruhi intensi anti korupsi seseorang yaitu faktor internal individu, yaitu lemahnya moral atau kurang kuatnya moral dalam diri individu dapat menjadi salah satu penyebab seseorang dalam melakukan tindak pidana korupsi. Kenyataan di atas didukung oleh penelitian yang dilakukan oleh Stachowitz (dalam Dayakisni, 2015), Stachowitz menjelaskan studi tentang kecenderungan atau perilaku pelanggaran etika termasuk korupsi yang memfokuskan pada analisis level individu menemukan bahwa kecenderungan korupsi salah satunya dipengaruhi oleh kurangnya integritas moral, identitas moral, dan perkembangan kognitif moral.

Nihayah, Adriani, dan Wahyuni (2015), dalam penelitiannya menjelaskan bahwa integritas moral berhubungan positif dengan intensi anti-korupsi. Dimana semakin tinggi tingkat integritas moral seseorang maka semakin tinggi tingkat intensi anti-korupsinya. Individu yang memiliki integritas moral tinggi akan menjauhkan dirinya dari perilaku korupsi. Integritas merupakan inti penentu sikap percaya di dalam hubungan kerja organisasi dan nilai kerja. Integritas dapat juga dikaitkan dengan komitmen Pemerintah untuk menyelenggarakan pemerintahan yang bersih dari praktik korupsi (Wisesa, 2011).

Selain rendahnya moral, banyak faktor internal yang dapat mempengaruhi seseorang untuk melakukan tindak pidana korupsi yaitu salah satunya adalah pengaruh gaya hidup (Abidin, dalam KP2KKN Jawa Tengah, 2011). Gaya hidup berlebihan para pejabat dapat menjadi satu penanda bahwa pejabat yang bersangkutan berkelakuan tidak baik, biasanya berkaitan dengan korupsi. Akibat terpancing untuk memiliki gaya hidup mewah, sering para pejabat menghalalkan segala cara.

Busyro Muqoddas mengkritik perilaku hidup mewah anggota DPR. Perilaku gaya hidup mewah bisa menjadi awal tumbuhnya tindak korupsi. Gaya hidup mewah bisa mendorong sifat dan rasa tidak puas dari pelakunya, sehingga 
akhirnya dapat memenuhi ketidakpuasan dengan berbagai cara, termasuk melakukan korupsi (BeritaSatu.com, 2011).

Penelitian Larasati (2014) mengenai pengaruh gaya hidup terhadap kecenderungan anti korupsi di Komisi Yudisial, menemukan bahwa gaya hidup mewah berpengaruh negatif secara signifikan terhadap kecenderungan anti korupsi. Semakin tinggi gaya hidup mewah seseorang maka tingkat kecenderungan anti korupsinya semakin rendah. Jadi, tingkat kecenderungan atau intensi anti korupsi dapat ditingkatkan dengan cara mengurangi gaya hidup yang terlalu bermewah-mewahan.

Di sisi lain, faktor yang dapat mendukung terjadinya perilaku korupsi yaitu faktor eksternal, seperti budaya organisasi. Korupsi dapat terjadi di dalam organisasi apabila dalam organisasi tersebut tidak terdapat kultur atau budaya organisasi yang benar. Setiap organisasi memiliki aturan, karakteristik, serta budayanya sendiri. Budaya organisasi (organizational culture) dibangun berdasarkan interaksi antar anggota organisasi. Budaya organisasi secara konsisten menjadi frame berperilaku para anggotanya sehingga dari sana identitas kelompok terbentuk. Budaya organisasi biasanya punya pengaruh kuat terhadap anggotanya. Apabila budaya organisasi tidak dikelola, akan menimbulkan berbagai situasi tidak kondusif mewarnai kehidupan organisasi. Pada posisi demikian, perbuatan negatif seperti korupsi dapat terjadi. (Rahmi, 2014).

Penelitian yang dilakukan oleh Domoro dan Agil (2012) mendukung pendapat di atas, dimana hasil penelitian tersebut menunjukkan bahwa budaya organisasi yang ada pada kepolisian Libya berpengaruh negative terhadap perilaku korupsi para anggota polisi tersebut. Campbell dan Goritz (2014) menjelaskan dalam penelitiannya, berkenaan dengan perilaku korupsi aktif dan korupsi pasif, budaya organisasi dapat menjembatani proses normalisasi korupsi di organisasi yang bersangkutan. Itu artinya dengan adanya normalisasi korupsi tersebut, atasan atau pimpinan yang ada di dalam organisasi membiarkan begitu saja korupsi yang terjadi di organisasi tersebut, sehingga budaya korupsi semakin merajalela dalam organisasi.

Dari beberapa hasil penelitian di atas, mengenai hubungan budaya organisasi terhadap korupsi dapat ditarik kesimpulan bahwa organisasi yang memiliki budaya kuat untuk melawan dan bersikap negatif terhadap korupsi maka budaya tersebut dapat mempengaruhi sikap para anggota organisasi terhadap korupsi. Untuk meningkatkan intensi anti korupsi di dalam organisasi diperlukan budaya organisasi yang mendukung anti korupsi tersebut sebagai salah satu bentuk tindakan untuk menghindari diri dari perilaku korupsi.

Sebenarnya di Indonesia terdapat beberapa kebijakan pemerintah untuk mencegah dan menangani perilaku korupsi, antara lain UU Nomor 28 Tahun 1999 tentang Penyelenggaraan Negara yang Bersih dan Bebas Korupsi, Kolusi dan Nepotisme (KKN), adanya Tim Gabungan Pemberantasan Tindak Pidana Korupsi (TGPTPK) tahun 2000, dan pembentukan Komisi Pemberantasan Korupsi (KPK) pada tahun 2006 (Karsona dalam Yuwanto, 2016). Kebijakan pemerintah tersebut merupakan strategi pembentukan lembaga antikorupsi. Korupsi memang tidak akan bisa benar-benar dihilangkan, namun paling tidak 
harapan untuk mengurangi korupsi seharusnya dapat segera terwujud (Yuwanto dalam Yuwanto, 2015).

Untuk mengetahui perilaku anti korupsi masyarakat di Indonesia bisa menggunakan data Indeks Perilaku Anti Korupsi (IPAK) yang di keluarkan oleh Badan Pusat Statistik pada tahun 2017. Indeks Perilaku Anti Korupsi (IPAK) Indonesia 2017 sebesar 3,71 pada skala 0 sampai 5. Nilai indeks semakin mendekati 5 menunjukkan bahwa masyarakat berperilaku semakin anti korupsi, sebaliknya nilai IPAK yang semakin mendekati 0 menunjukkan bahwa masyarakat berperilaku semakin permisif terhadap korupsi. IPAK disusun berdasarkan dua dimensi utama yakni persepsi dan pengalaman. Indeks persepsi dan pengalaman cenderung meningkat dari kondisi tahun 2015 ke 2017. Hal ini menggambarkan bahwa pemahaman dan penilaian masyarakat terhadap anti korupsi semakin baik (Badan Pusat Statistik, 2017).

Meskipun terdapat kelaziman dan dampak buruk, melakukan penelitian tentang korupsi telah dianggap memiliki hasrat ilmiah untuk diketahui, karena untuk mendapatkan informasi yang benar tentang luasnya kegiatan korupsi di pasar barang dan tenaga kerja merupakan hal yang sulit, karena individu yang terlibat dalam kegiatan tersebut berharap untuk tidak diidentifikasi (Dreher dan Schneider dalam Basheka dan Tumutegyereize, 2011). Berdasarkan pendapat tersebut, dalam hal ini peneliti mempertimbangkan akan melakukan penelitian mengenai intensi anti korupsi. Dalam penelitian yang dilakukan oleh Nihayah, Wahyuni dan Adriani (2015) dijelaskan bahwa intensi anti-korupsi merupakan intensi individu untuk menolak korupsi.

\section{METODE PENELITIAN}

\section{Populasi, sampel dan teknik pengambilan sampel}

Populasi dalam penelitian ini adalah pegawai di lembaga kepolisian X yang terdiri dari anggota polisi dan PNS Polri. Jumlah anggota populasinya sebanyak kurang lebih 200 pegawai. Dan jumlah sampel dalam penelitian ini adalah sebanyak 151 orang. Dalam Penelitian ini, teknik pengambilan sampel yang digunakan adalah teknik convenience sampling yang tergolong dalam teknik non probability sampling. Teknik ini penulis pilih karena proses pengambilan data tidak dilakukan secara langsung oleh penulis melainkan melalui salah satu pegawai yang telah ditugaskan. Hal tersebut juga didasarkan dengan pertimbangan keterbatasan waktu, tenaga dan menyesuaikan dengan kebijakan lembaga terkait.

\section{Instrumen penelitian}

Skala yang digunakan adalah skala intensi anti korupsi, integritas moral, gaya hidup dan budaya organisasi menggunakan model Likert dengan skala 1-4.

\section{Alat Ukur Intensi Anti Korupsi}

Skala intensi anti korupsi yang digunakan adalah skala Intensi Anti Korupsi yang disusun oleh peneliti sebanyak 24 item dengan favorable item berjumlah 12 item dan unfavorable item berjumlah 12 item. Skala Intensi Anti Korupsi ini menggunakan aspek intensi yang dikemukakan oleh oleh Fishbein dan Ajzen (1975) yang meliputi tindakan, sasaran, situasi, dan waktu yang berkaitan dengan intensi anti korupsi. 
2. Alat Ukur Integritas Moral

Integritas moral dalam penelitian ini diukur menggunakan alat ukur yang disusun oleh peneliti dengan mengacu pada Moral Integrity Survey (MIS) dari Olson (1998) yang telah dimodifikasi oleh Nihayah, Adriani, dan Wahyuni (2015) dan Rahman (2013). Skala ini terdiri dari 18 item.

3. Alat Ukur Gaya Hidup

Alat ukur gaya hidup yang digunakan pada penelitian ini adalah alat ukur yang peneliti buat sendiri mengacu pada psikografik AIO (Activities, Interest, dan Opinion) yang dikembangkan oleh Plummer (1974), dimana di dalam psikografi tersebut terdapat tiga dimensi, yaitu aktivitas, minat, dan opini, dan kemudian gaya hidup dikelompokan menjadi salah satu jenis gaya hidup, yaitu gaya hidup mewah.

4. Alat Ukur Budaya Organisasi

Alat ukur yang digunakan untuk mengukur budaya organisasi dalam penelitian ini adalah alat ukur berbentuk skala likert yang kembangkan oleh Denison dan Neale (1997) yang telah diadaptasi dan disederhanakan oleh peneliti menjadi 34 item yang mewakili keempat dimensi budaya organisasi.

\section{HASIL PENELITIAN}

\section{Hasil Uji Hipotesis}

1. Uji hipotesis mayor

Pada tahapan ini peneliti menguji hipotesis dengan teknik analisis regresi berganda dengan menggunakan software SPSS 17.

Tabel Modal Summary

\begin{tabular}{lcccc}
\hline Model & R & R Square & Adjusted R Square & Std. Error of the Estimate \\
\hline 1 &, $750^{\mathrm{a}}$ &, 563 &, 538 & 6,48508 \\
\hline
\end{tabular}

Predictors: (Constant), moral discernment, consistent behavior, public justification, gaya hidup mewah, involveme'nt, consistency, adaptability, dan mission.

Pada tabel tersebut dapat dilihat bahwa diperoleh R-Square sebesar 0.563 atau $56,3 \%$. Artinya, proporsi varian dari intensi anti korupsi yang dijelaskan oleh integritas moral (moral discernment, consistent behavior, dan public justification), gaya hidup (gaya hidup mewah) dan budaya organisasi (involvement, consistency, adaptability, dan mission) adalah sebesar 56,3\%, sedangkan $43,7 \%$ sisanya dipengaruhi oleh variabel lain di luar penelitian ini.

\section{Anova Keseluruhan IV terhadap DV}

\begin{tabular}{lcccc}
\hline \multicolumn{4}{c}{ ANOVA $^{\mathbf{b}}$} & \\
Model & Sum of Squares & df & Mean Square & Sig. \\
\hline Regression & 7690,517 & 8 & 961,315 & $0,00^{\mathbf{a}}$ \\
Residual & 5971,991 & 142 & 42,056 & \\
Total & 16405.756 & 179 & & \\
\hline
\end{tabular}

a. Predictors: (Constant), moral discernment, consistent behavior, public justification, gaya hidup mewah, involvement, consistency, adaptability, dan mission. 
Berdasarkan uji $\mathrm{F}$ pada tabel diatas, dapat dilihat bahwa nilai $\mathrm{p}$ (Sig.) pada kolom paling kanan adalah $\mathrm{p}=0.000$ dengan nilai $\mathrm{p}<0.05$. Jadi, dengan demikian hipotesis nihil $\left(\mathrm{H}_{0}\right)$ yang berbunyi "tidak ada pengaruh yang signifikan integritas moral, gaya hidup, dan budaya organisasi terhadap intensi anti korupsi" ditolak. Artinya ada pengaruh yang signifikan integritas moral (moral discernment, consistent behavior, dan public justification), gaya hidup (gaya hidup mewah) dan budaya organisasi (involvement, consistency, adaptability, dan mission).

\section{Koefisien regresi masing-masing IV}

\begin{tabular}{lccc}
\hline Model & $\begin{array}{c}\text { Unstandardized } \\
\text { Coefficients }\end{array}$ & $\begin{array}{c}\text { Standardized } \\
\text { Coefficients }\end{array}$ & Sig. \\
\cline { 2 - 4 } & $\mathrm{B}$ & Beta & \\
\hline (Constant) & 40.260 & &, 000 \\
Moral Discernment &,- 130 &,- 124 &, 120 \\
Consistent Behavior &, 244 &, 230 &, $007^{*}$ \\
Public Justification &, 003 &, 003 &, 963 \\
Gaya H idup Mewah &,- 376 &,- 361 &, $000^{*}$ \\
Involvement &, 091 &, 088 &, 284 \\
Consistency &, 101 &, 097 &, 324 \\
Adaptability &,- 066 &,- 063 &, 457 \\
Mission &, 329 &, 320 &, $002^{*}$ \\
\hline
\end{tabular}

Berdasarkan pada table koefisien regresi, dapat dijelaskan bahwa terdapat tiga koefisien regresi yang signifikan, yaitu consistent behavior, gaya hidup mewah dan mission. Sementara lima variabel lainnya tidak signifikan.

\section{Proporsi varian}

1. Variabel moral discernment memberikan sumbangan sebesar $8,1 \%$ dalam varians intensi anti korupsi dan memiliki nilai $F=13,110, \mathrm{df} 1=1, \mathrm{df} 2=149$ dan sig. $F$ change $=0,000$.

2. Variabel consistent behavior memberikan sumbangan sebesar $13 \%$ dalam varians intensi anti korupsi dan memiliki nilai $\mathrm{F}=24,277, \mathrm{df} 1=1$, df2 $=148$ dan sig. F change $=0,000$.

3. Variabel public justification memberikan sumbangan sebesar $2 \%$ dalam varians intensi anti korupsi dan memiliki nilai $\mathrm{F}=3,808$, df1=1, df2=147 dan sig. $F$ change $=0,053$.

4. Variabel gaya hidup mewah memberikan sumbangan sebesar $20,8 \%$ dalam varians intensi anti korupsi dan memiliki nilai $\mathrm{F}=54,230, \mathrm{df} 1=1, \mathrm{df} 2=146$ dan sig. $F$ change $=0,000$.

5. Variabel involvement memberikan sumbangan sebesar $6,3 \%$ dalam varians intensi anti korupsi dan memiliki nilai $\mathrm{F}=18,222$, df1 $=1, \mathrm{df} 2=144$ dan sig. $F$ change $=0,000$.

6. Variabel consistency memberikan sumbangan sebesar $3,1 \%$ dalam varians intensi anti korupsi dan memiliki nilai $\mathrm{F}=9,568, \mathrm{df} 1=1$, df2=143 dan sig. $F$ change $=0,002$. 
7. Variabel adaptability memberikan sumbangan sebesar $0,1 \%$ dalam varians intensi anti korupsi dan memiliki nilai $\mathrm{F}=0,190, \mathrm{df} 1=1$, df2 $=142$ dan sig. $F$ change $=0,663$.

8. Variabel mission memberikan sumbangan sebesar $3 \%$ dalam varians intensi anti korupsi dan memiliki nilai $\mathrm{F}=9,671$, df1=1, df2=141 dan sig. $F$ change $=$ 0,002 .

\section{Kesimpulan}

\section{KESIMPULAN DAN SARAN}

Berdasarkan hasil analisis data penelitian yang telah peneliti jelaskan pada bab 4, maka kesimpulan yang dapat diambil dari penelitian ini adalah "ada pengaruh yang signifikan antara variabel integritas moral (moral discernment, consistent behavior, dan public justification), gaya hidup (gaya hidup mewah), dan budaya organisasi (involvement, consistency, adaptability, dan mission) terhadap intensi anti korupsi pada pegawai (polisi dan PNS polri) lembaga kepolisian X”. Dengan demikian, hipotesis mayor pada penelitian ini diterima.

Berdasarkan hasil uji hipotesis setiap variabel, terdapat tiga variabel independen yang signifikan pengaruhnya terhadap intensi anti korupsi, yaitu consistent behavior, gaya hidup mewah, dan mission. Tetapi, apabila dilihat dari signifikan atau tidaknya proporsi varian sumbangan kontribusi setiap independen variabel terdapat enam variabel yang signifikan memberikan sumbangan dengan nilai terbesar sampai terkecil yaitu variabel consistent behavior, gaya hidup mewah, moral discernment, involvement, consistency, mission, dan artinya terdapat dua variabel independen yang tidak signifikan yaitu adaptability, dan public justification.

\section{Diskusi}

Berdasarkan hasil pengujian hipotesis yang telah dikemukakan diperoleh hasil bahwa terdapat pengaruh yang signifikan integritas moral (moral discernment, consistent behavior, dan public justification), gaya hidup (gaya hidup mewah), dan budaya organisasi (involvement, consistency, adaptability, dan mission) terhadap intensi anti korupsi dengan signifikansi 0,000 dan nilai kontribusi variabel independen terhadap variabel dependen sebesar 0,563 atau $56,3 \%$. Hal ini menunjukkan bahwa integritas moral, gaya hidup, dan budaya organisasi memiliki pengaruh yang signifikan terhadap intensi anti korupsi sebesar 56,3\% dan sisanya $43,7 \%$ dipengaruhi oleh variabel lain diluar penelitian ini.

Berdasarkan koefisien regresi setiap independent variable menunjukkan bahwa terdapat pengaruh yang signifikan consistent behavior, gaya hidup mewah, dan mission terhadap intensi anti korupsi. Sedangkan variabel moral discerment, public justification, involvement, consistency, dan adaptability pengaruhnya tidak signifikan terhadap intensi anti korupsi.

Dimensi moral discernment dari variabel integritas moral pengaruhnya tidak signifikan terhadap intensi anti korupsi. Hal tersebut tidak sejalan dengan penelitian yang dilakukan oleh Nihayah, Adriani, dan Wahyuni (2015), yaitu adanya pengaruh yang signifikan antara moral discernment terhadap intensi anti korupsi. Olson (1998) menyebutkan bahwa moral discernment mengacu pada 
kemampuan seseorang untuk membedakan secara moral mana yang baik dan yang buruk bagi dirinya maupun orang lain. Menurut Olson (dalam Rahman, 2013), orang yang memiliki integritas moral (moral discernment) tinggi biasanya memiliki keyakinan moral yang jelas, dan mampu berkomitmen serta selalu konsisten terhadap keyakinannya tersebut. Dari pendapat Olson tersebut, dapat dijelaskan mengapa hasil dari penelitian ini berbeda dengan hasil penelitian sebelumnya, hal ini mungkin dapat terjadi karena para anggota polisi dan PNS polri pada lembaga kepolisian $\mathrm{X}$ belum sepenuhnya mampu mengenali dan memahami apa yang menjadi keyakinan-keyakinan bagi diriya, dan mungkin juga hal tersebut terjadi diakibatkan responden belum mengenali keyakinan dan nilai-nilai moral yang baik bagi dirinya maupun orang lain Maka dari itu moral discernment pada penelitian ini tidak memberikan pengaruh yang signifikan terhadap intensi anti korupsi.

Consistent behavior pengaruhnya signifikan terhadap intensi anti korupsi. Hal ini sejalan dengan penelitian sebelumnya yang dilakukan oleh Nihayah, Adriani dan Wahyuni (2015). Olson (1998) menjelaskan, consistent behavior mengacu pada kemampuan individu untuk melakukan suatu tindakan secara konsisten dengan keyakinanya kapan pun dan dimana pun, bahkan pada situasi yang berat sekali pun. Dalam penelitian ini, ditemukan bahwa dimensi consistent behavior memberikan pengaruh positif terhadap intensi anti korupsi.

Hasil penelitian menunjukkan bahwa public justification pengaruhnya tidak signifikan terhadap intensi anti korupsi. Hasil ini berbeda dengan hasil penelitian sebelumnya yang dilakukan oleh Nihayah, Adriani, dan Wahyuni (2015), bahwa public justification berpengaruh secara signifikan terhadap intensi anti korupsi. Public justification menunjuk pada kemampuan individu untuk dapat menyampaikan secara terbuka kepada orang lain mengenai keyakinan moral yang dimilikinya. Orang yang memiliki public justification yang tinggi tidak akan malu untuk menyampaikan dan berbagi mengenai keyakinan yang dimilikinya kepada orang lain (Olson, 1998). Perbedaan hasil yang diperoleh dalam penelitian ini dengan penelitian sebelumnya bisa saja terjadi karena para pegawai di lembaga kepolisian belum sepenuhnya berani atau masih terdapat rasa malu untuk berbagi keyakinan bahwa intensi anti korupsi merupakan hal yang baik untuk dilakukan dan merupakan salah satu cara untuk menghindari diri agar tidak terjerumus ke dalam pusaran korupsi.

Pada variabel gaya hidup, dimensi gaya hidup mewah memiliki pengaruh yang negatif dan signifikan terhadap intensi anti korupsi, hal tersebut dapat diartikan bahwa semakin tinggi gaya hidup mewah seseorang, maka akan semakin rendah tingkat intensi anti korupsinya. Hasil tersebut sesuai dengan hasil penelitian sebelumnya yang di lakukan oleh Larasati (2014), dimana terdapat pengaruh yang signifikan antara gaya hidup mewah terhadap intensi anti korupsi. Hal ini sesuai dengan pernyataan mantan ketua KPK Busyro Muqoddas (dalam Berita Satu, 2011), bahwa gaya hidup mewah bisa menjadi awal tumbuhnya tindak korupsi karena gaya hidup tersebut bisa mendorong sifat rasa tidak puas dari pelakunya sehingga akhirnya untuk memenuhi ketidakpuasan tersebut berbagai cara dapat dilakukan termasuk melakukan korupsi. 
Pada variabel budaya organisasi, hasil penelitian ini menunjukkan bahwa terdapat pengaruh yang signifikan antara budaya organisasi involvement, consistency, adaptability, dan mission terhadap intensi anti korupsi. Hal tersebut sejalan dengan penelitian yang dilakukan oleh Campbell dan Goritz (2014) yang menunjukkan bahwa budaya organisasi dapat menjembatani proses normalisasi korupsi di organisasi yang bersangkutan. Itu artinya dengan adanya normalisasi korupsi tersebut, atasan atau pimpinan yang ada di dalam organisasi membiarkan begitu saja korupsi yang terjadi di organisasi tersebut, sehingga budaya korupsi semakin merajalela dalam organisasi.

Pada variabel budaya organisasi, dimensi yang pertama adalah involvement. Hasil dalam penelitian ini involvement tidak memiliki pengaruh yang signifikan terhadap intensi anti korupsi. Denison dan Neale (1997) menjelaskan, budaya organisasi yang memiliki budaya dengan ciri "highly involved" sangat mendorong keterlibatan karyawan, dan menciptakan rasa memiliki dan bertanggung jawab. Dari rasa kepemilikan ini tumbuh komitmen yang lebih besar terhadap organisasi dan peningkatan kapasitas untuk otonomi. Menerima masukan dari anggota organisasi dapat meningkatkan kualitas keputusan dan memperbaiki implementasinya. Apabila dikaitkan dengan penelitian ini, involvement tidak memberi pengaruh yang signifikan terhadap intensi anti korupsi mungkin saja dapat disebabkan karena masih kurangnya keterlibatan para pegawai terhadap pekerjaannya maupun keterlibatannya di dalam lembaga tempatnya bekerja. Hal tersebut mungkin dapat mengakibatkan para pegawai tidak perduli dengan berbagai hal yang terjadi di dalam lembaganya tersebut.

Consistency pengaruhnya tidak signifikan terhadap intensi anti korupsi. Konsistensi dapat menciptakan budaya organisasi yang kuat berdasarkan sistem keyakinan, nilai dan simbol bersama yang telah dipahami secara luas oleh anggota organisasi. Denison dan Neale (1997) menjelaskan bahwa organisasi mampu mengembangkan pola pikir dan sistem organisasi internal berdasarkan pada dukungan konsensual. Organisasi yang mampu menerapkan dapat menghasilkan karyawan yang berkomitmen tinggi dan dapat memahami secara jelas mengenai apa saja yang boleh dan dialarang dilakukan di dalam organisasi. Apabila terdapat budaya yang konsisten untuk menerapkan intensi anti korupsi dalam sebuah organisasi maka nantinya para karyawannya juga dapat konsisten dengan keyakinannya untuk mengikuti dan menanamkan perilaku anti korupsi dalam dirinya.

Adaptability pengaruhnya tidak signifikan terhadap intensi anti korupsi. Menurut Denison dan Neale (1997), organisasi memegang sistem norma dan kepercayaan yang mendukung kapasitas organisasi untuk menerima, menafsirkan, dan menerjemahkan sinyal dari lingkungannya ke dalam perubahan perilaku internal untuk meningkatkan peluangnya untuk bertahan hidup, tumbuh dan berkembang. Kaitannya dengan anti korupsi yaitu jika organisasi dan para anggotanya mampu beradaptasi dengan kondisi Indonesia saat ini yang marak dengan kasus korupsi dapat memungkinkan organisasi mampu mengembangkan nilai-nilai dan perilaku anti korupsi.

Hasil penelitian menunjukkan bahwa mission memiliki pengaruh yang signifikan terhadap intensi anti korupsi. Denison dan Neale (1997) menjelaskan, 
mission menyediakan tujuan dan makna dengan mendefinisikan peran sosial dan tujuan eksternal organisasi. Mission dapat memberikan arahan dan sasaran yang jelas berfungsi untuk menentukan tindakan yang tepat bagi organisasi dan anggotanya. Apabila anggota organisasi mampu memahami misi organisasi yang berkaitan dengan anti korupsi, akan dapat membantu diri sendiri serta organisasi untuk menghindari korupsi dan meningkatkan anti korupsi.

\section{DAFTAR PUSTAKA}

Ajzen, I. (2005). Attitudes, personality, and behavior. New York: Open University Press.

Ajzen, I \& Fishbein, M. (1975). Belief, attitude, intention, and behavior: An Introduction to Theory and Research. Massachusetts: Adison-Willey

Ageev, I. A., \& Ageeva, V. V. (2015). Urban lifestyle as an element of consumption ideal and economic wellbeing: meaning-changing transformation from Soviet period to moderenity. Procedia-Social and Behavioral Science, 166, 24-29. doi: $0.1016 / j . s b s p r o .2014 .12 .477$

Ancok, D. (2004). Korupsi: sekelumit visi psikologi. Yogyakarta: Darussalam

Ahmad, M. S. (2012). Impact of organizational culture on performance management practices in Pakistan. Bussines Intelligence Journal, 7 (2), 50-55.

Alawiyah, Tuti. (2015). Uji validitas konstruk pada instrumen Big Five Inventory (BFI) dengan metode Confirmatory Factor Analysis (CFA). Jurnal Pengukuran Psikologi dan Pendidikan Indonesia, 4 (3), 215-230.

Badan Pusat Statistik. (2017). Indeks perilaku anti korupsi indonesia 2017. Jakarta: Badan Pusat Statistik

Benon C Basheka, \& Milton Tumutegyereize . (2011). Determinants of public procurement corruption in uganda : a conceptual framework. Journal of Public Procurement, Issue 2, 33-60.

Campbell, J., \& Goritz, A. (2014). Culture corrupts! a qualitative study of organizational culture in corrupt organizations. Journal of Bussines Ethics, 120 (3), 291-311.

Darsana, M. (2013). The influence of personality and organizational culture on employee performance through organizational citizenship behavior. The International Journal of Management, 2 (4), 35-42.

Dayakisni T. (2015). Hubungan sinisme sosial dengan sikap remaja terhadap korupsi. Paper dipresentasikan pada seminar psikologi dan kemanusiaan forum psikologi Universitas Muhamadiyah, Malang.

Denison, Daniel R., \& Neale, William S. (1997). Denison organizational culture survey. Washington : Denison Consulting.

Dunn, C. P. (2009). Integrity matters. International Journal of Leadership Studies, 5 (2), 102124.

Domoro, O. M., \& Agil, S. O. (2012). The influence of organizational culture on police corruption in Libya. IOSR Journal of Business and Management, 2 (5), 33-38.

Hawkins, D. L., \& Mothersbaugh, D. L. (2010). Consumer behavior: building market strategy. New York : Mc-Graw Hill.

Floyd, Frank F., \& Widaman, Keith F. (1995). Factor analysis in the development and refinement of clinical assessment instrument. Journal of Psychological Assessment, 7 (3), 286-299.

Komisi Pemberantasan Korupsi. (2016). Rekapitulasi tindak pidana. Jakarta: Anti Corruption Clearing House 
Komisi Pemberantasan Korupsi. (2015). Survei integritas sektor publik 2014 fakta korupsi dalam layanan publik. Jakarta: Direktorat Penelitian dan Pengembangan Kedeputian Bidang Pencegahan Komisi Pemberantasan Korupsi.

Larasati, I. (2014). Pengaruh religiusitas, locus of control, dan gaya hidup terhadap kecenderungan anti korupsi. Skripsi. Fakultas Psikologi Universitas Islam Negeri Syarif Hidayatullah, Jakarta.

Lin, L.-Y., \& Shih, H.-Y. (2012). The relationship of university student's lifestyle, money attitude, personal value and their purchase decision. International Journal of Research In Management, 1 (2), 19-37.

Munandar. (2001). Psikologi industri dan organisasi. Jakarta: UI Press.

Olson, L. M. (1998). The relationship between moral integrity, pscyhological well-being, and anxiety. Wisconsin: Wisconsin University.

Pedhazur, E. J. (1982). Multiple regression in behavioral research: Explanation and prediction second edition. USA: CBS Collage Publishing.

Plummer, J. T. (1974). The concept and application of lifestyle segmentation. Journal of Marketing, 38 (1), 33-37. doi: 10.2307/1250164.

Rahman, A. A. (2013). Prinsip kesucian, kemunafikan, dan integritas moral. Disertarsi. Fakultas Psikologi Universitas Indonesia, Jakarta.

\section{Website}

Abidin, Z. (2011). Psikologi Korupsi Dan Pembentukan Karakter Bangsa. Diakses pada 3 Februari 2017, dari KP2KKN Jawa Tengah: https://antikorupsijateng.wordpress.com/2011/08/26/psikologi-korupsi-danpembentukan-karakter-bangsa/

BeritaSatu.com. (2011). Mahfud MD: Pejabat Bergaya Hidup Mewah Berpotensi Korupsi. Diakses pada 1 Februari 2017, dari http://www.beritasatu.com/politik/17435mahfud-md-pejabat-bergaya-hidup-mewah-berpotensi-korupsi.html

Indonesia Corruption Watch (2008). Mantan Kapolri Tersangka; Jenderal Rusdihardjo Terjerat Kasus Pungli Saat Menjadi Dubes Malaysia. Diakses pada 1 Februari 2017, dari http://www.antikorupsi.org/id/content/mantan-kapolri-tersangka-jenderalrusdihardjo-terjerat-kasus-pungli-saat-dubes-malaysia.

Komisi Pemberantasan Korupsi. (2013). Djoko Susilo Terbukti Korupsi Dan Cuci Uang. Diakses pada 1 Februari 2017, dari https://www.kpk.go.id/id/berita/beritasub/1334-djoko-susilo-terbukti-korupsi-dan-cuci-uang.

Merah Putih. (2016). Hasil Survei: Polri Lembaga Negara Paling Korup Di Indonesia. Diakses pada 28 Desember 2016, dari http://merahputih.com/post/read/hasil-surveipolri-lembaga-negara-paling-korup-di-indonesia.

Republika.co.id. (2017). Survei Tunjukkan Kepolisian Lembaga Paling Korup. Diakses pada 14 Maret 2017, dari http://nasional.republika.co.id/berita/nasional/hukum/17/03/07/omfsg1361survei-tunjukkan-kepolisian-lembaga-paling-korup

Viva.co.id. (2013). Ini Akar Kasus Yang Mengirim Jenderal Susno Ke Bui. Diakses pada 1 Februari 2017, dari http://nasional.news.viva.co.id/news/read/410179-ini-akarkasus-yang-mengirim-jenderal-susno-ke-bui. 